\title{
ENZYMATIC SYNTHESIS OF HYDROPHOBIC COMPOUNDS INTEGRATED WITH MEMBRANE SEPARATION
}

\author{
Andrzej Noworyta, Anna Trusek-Holownia* \\ Wroclaw University of Technology, Department of Chemistry, Division of Bioprocess and \\ Biomedical Engineering, Wybrzeze Wyspianskiego 27, 50-370 Wroclaw, Poland \\ Dedicated to Prof. Ryszard Pohorecki on the occasion of his 80th birthday
}

\begin{abstract}
The enzymatic synthesis of a highly hydrophobic product (dipeptide precursor) in which the reaction is accompanied by the mass transfer of the reaction product to the organic phase and the substrates to the water phase is considered. Equations describing both continuous and batch processes are formulated. The range of variability in the operating parameters of such a bioreactor is specified, and the correlations reported in the literature to describe mass transfer in the membrane contactor are validated. The proposed process was verified experimentally, and good agreement between the determined and calculated concentrations was obtained in both phases.
\end{abstract}

Keywords: membrane contactor; product extraction; mathematical model

\section{INTRODUCTION}

There is a relatively large group of reactions, especially in biotechnology, in which some of the reactants are poorly soluble in the reaction system. A method to increase the efficiency of such reactions is to perform them in a two-phase system, in which one phase is a reaction phase and the other one is a reservoir of reactants that are poorly soluble in the reaction phase. In such a case, the two simultaneous processes are integrated: chemical (biochemical) reaction and extraction.

Due to the requirements for enzyme activity and microorganism functioning, the reaction phase in biotechnological processes consists of the water phase, except for the systems that involve lipases (Dabrowska et al., 2012; Trusek-Holownia and Noworyta, 2007). The delivery of the product to the organic phase is dependent on separating it from other reactants, including mixtures of enantiomers (Huang et al., 2004; Jin et al., 2003; Ma et al., 2006; Nomoto et al., 2003), shifting the reaction equilibrium to favour the products (Hossain et al., 2008, Vu et al., 2013; Wasewar et al., 2004), and preventing the precipitation of a hydrophobic product in the reaction phase after the saturation concentration is exceeded (Jakubke et al., 1985). Extraction of the product to the organic phase was applied for both microbiological processes (Hossain et al., 2008; Huang et al., 2004, Ma et al., 2006) and enzymatic reactions (Penci et al., 2010; Villa et al., 2005; Vu et al. 2013; Yankov et al., 2004).

Conventionally, two-phase processes are performed in disperse systems in a mixer or column (Cunha and Aires-Barros, 2002; Pohorecki et al., 2001). In each of these cases, the coalescence of the extraction system to restore the compact phases is required. This requires the use of settlers with relatively high capacities, which can be a problem for the experimental apparatus and cause uncontrolled residence of the reaction phase outside the reactor. Moreover, when an extraction column 
is used, problems with phase flow and column flooding can occur. For these reasons, the integration of the chemical (biochemical) reaction with the classical extraction process is problematic and technologically inefficient. One method for the effective integration of the processes described above is the use of membrane contactors (Huang et al., 2004; Sisak et al., 2000).

A typical membrane contactor is composed of a bundle of capillary membranes, and its construction is similar to that of a shell-and-tube heat exchanger. It consists of porous membranes, usually microfiltration membranes (Koltuniewicz et al., 2012) in which the pore surface acts as the mass transfer area. The resulting large interface surface area, which can be up to several hundred $\mathrm{m}^{2} / \mathrm{m}^{3}$, is one of the main advantages of the membrane phase contactor. Both phases flow continuously through the membrane contactor. The lack of dispersion of the phases eliminates the need for coalescence, which is undoubtedly another advantage of constructing the apparatus in this manner. Unlike extraction columns, the continuous flow of both phases allows for higher flow rates of the two phases to be used, resulting in an increase in the mass transfer coefficients (Agrahari et al., 2011). Considering the advantages of the membrane contactor, it should be noted that it is an extremely simple device whose construction is not technically problematic.

Negative features of the membrane phase contactor include the additional diffusion resistance of mass transport through membrane pores. This disadvantage may be reduced by using a membrane made from a material with suitable hydrophobicity/hydrophilicity, which allows the membrane pores to be filled with a phase in which the transported component has a lower resistance to mass transfer. The benefits resulting from a significant development in the interface and the increased turbulence (e.g., compared to a typical flow in extraction columns) compensate for the additional mass transfer in the membrane. Another phenomenon that may adversely affect the process in some cases is known as membrane leakage. This occurs at very large flow rates of phases and in membranes with a high length-todiameter ratio, which lead to a relatively large pressure drop (approximately $10^{4} \mathrm{~Pa}$ ) along the flow path. This results in a transmembrane pressure that, in the case of porous membranes, causes flow of a given phase through pores in the direction of the pressure drop (just as in microfiltration processes). This effect may be reduced by using an appropriate static pressure on the other side of the membrane, as well as a proper design of the contactor (Kołtuniewicz et al., 2012).

In the literature there are correlations to determine the mass transfer coefficient in membrane contactors. And so, for the phase flowing through tubes the following correlations are used (Cerovsky and Martinek, 1989; Ceynowa 1974; Matsumae et al., 1994).

$$
\begin{gathered}
\left.S h=\frac{\beta d_{i n}}{D}=1.5\left(\frac{d_{\text {in }}}{H} \operatorname{Re} S c\right)^{0.33} \text { (hydrophobic membrane, } 8<S h<40\right) \\
\left.S h=\frac{\beta d_{\text {in }}}{D}=1.64\left(\frac{d_{\text {in }}}{H} \operatorname{Re} S c\right)^{0.33} \text { (hydrophobic membrane, } 5<G r<500\right) \\
S h=\frac{\beta d_{\text {in }}}{D}=1.62\left(\frac{d_{\text {in }}}{H} \operatorname{Re} S c\right)^{0.33}(G r>4)
\end{gathered}
$$

For the phase flowing through the intertubular space of the capillary module, the so-called shell side (the flow parallel to membranes) the following correlations are used (Anzai et al., 1989; Cerovsky and Jakubke, 1994; Ceynowa, 1974; Chang and Furusaki, 1991).

$$
\begin{gathered}
S h=\frac{\beta d_{\text {hydr. }}}{D}=0.019 \frac{d_{\text {hydr. }}}{H} \operatorname{ReS} c^{0.33}(G r<60) \\
S h=\frac{\beta d_{\text {hydr. }}}{D}=5.85 \frac{d_{\text {hydr. }}}{H}(1-\varphi) \operatorname{Re}^{0.6} S c^{0.33}(\operatorname{Re}<1000, \varphi<0.26)
\end{gathered}
$$




$$
\begin{gathered}
S h=\frac{\beta d_{h y d r .}}{D}=1.25\left(\operatorname{Re} \frac{d_{\text {hydr. }}}{H}\right)^{0.93} S c^{0.33}(\operatorname{Re}<1000) \\
S h=\frac{\beta d_{\text {hydr. }}}{D}=8.8 \frac{d_{\text {hydr. }}}{H} \operatorname{Re} S c^{0.33}(\operatorname{Re}<1000) \\
S h=\frac{\beta d_{\text {hydr. }}}{D}=3.66+1.61\left(\frac{d_{\text {in }}}{H} \operatorname{Re} S c\right)^{0.33}(0.1<G r<1000)
\end{gathered}
$$

A synthesis of highly hydrophobic substances collected from the reaction zone during the process was conducted. Because of its nature, the product can be almost completely extracted to a hydrophobic organic solvent in a membrane contactor. Tests were performed for the most interesting case, i.e., a highly hydrophobic product and substrates with mixed natures: one highly hydrophilic and the other one hydrophobic, i.e., supplied from the organic phase to the reaction (water) phase. Specifically, the synthesis of a dipeptide precursor catalysed by a protease selected based on its specificity was adopted as a model reaction. Recent studies have shown the particular importance of peptides with a defined sequence of amino acids in medicine as enzyme inhibitors (Sentandreu and Toldra, 2007), because of their antihypertensive (Vercruysse et al., 2008) and anxiolytic-like activities (Mizushige et al., 2013), and as peptidomimetic drug transporters (Peyne et. al., 2001).

\section{MATHEMATICAL MODEL OF AN ENZYMATIC REACTOR INTEGRATED WITH A MEMBRANE CONTACTOR}

In the presented system, there are two separately circulating phases: the water phase, which is generally the medium for enzymatic reactions or microbiological transformations, and the organic phase, which is typically a reservoir for the substrate that is poorly soluble in water or/and a receiver for the hydrophobic reaction product. A general scheme of such a system is shown in Fig. 1. Both phases may circulate in a closed system corresponding to the batch mode of operation. It is also possible to complete/receive used reagents in the continuous mode of operation. Substrates can be added to both water and organic phases. The hydrophobic product is delivered to the organic phase.

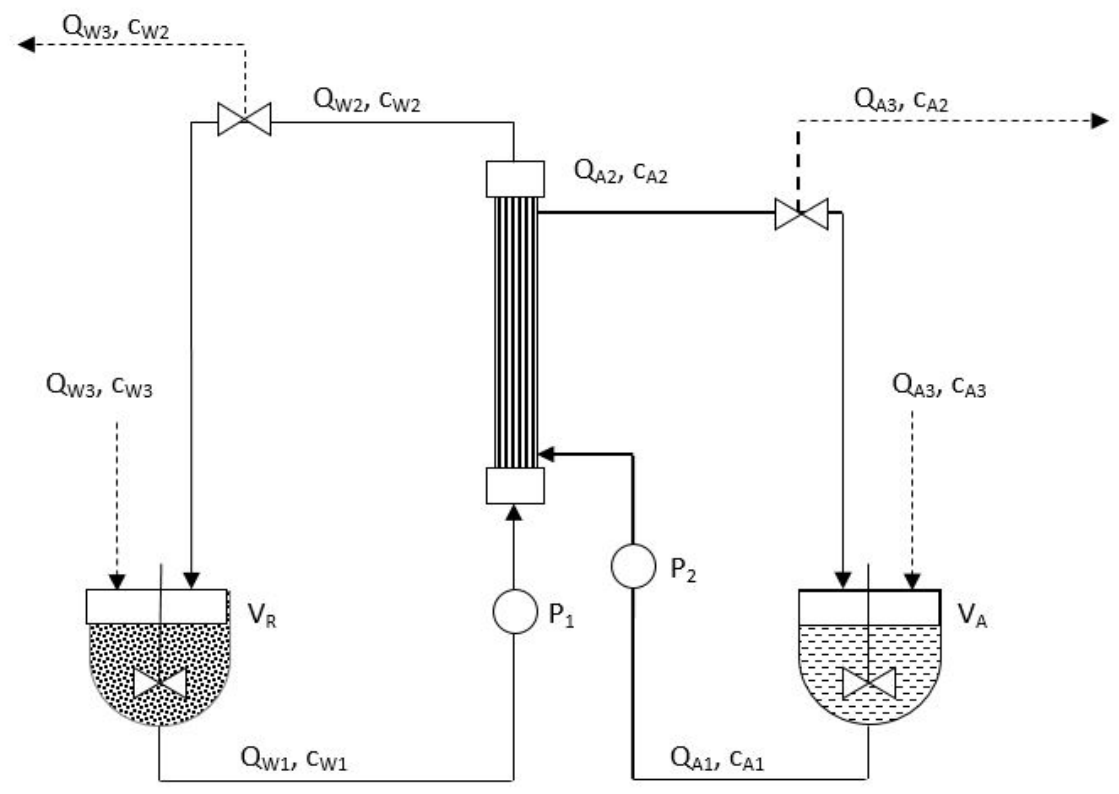

Fig. 1. Scheme of an integrated system working optionally at a batch or continuous system 
Unlike a chemical reaction, due to enzyme inactivation, irrespective of the mode of operation, the process takes place in unsteady state conditions. Hence, the description of a the system must refer to real time. In the general case the balance of the $i$-th component in the stirred tank reactor of volume $V_{R}$ has the form:

$$
\left(Q_{W 2}-Q_{W 3}\right) c_{W 2, i}(t) d t+Q_{W 3} c_{W 3, i} d t \pm V_{R} r_{i}(t) d t-Q_{W 1} c_{W 1, i}(t) d t=V_{R} d c_{W 1, i}
$$

The balance of the $i$-th component in the circulating tank of the organic phase is given by the equation:

$$
\left(Q_{A 2}-Q_{A 3}\right) c_{A 2, i}(t) d t+Q_{A 3} c_{A 3, i} d t-Q_{A 1} c_{A 1, i} d t=V_{A} d c_{A 1, i}
$$

Mass balance in the membrane contactor composed of a bundle of capillary membranes, under the assumption of plug flow, is:

- for the water phase, taking into account the reaction which occurs along the flow path:

$$
Q_{W 1} c_{W 1, i}\left(t-\tau_{k W}\right)-\int_{0}^{H} r_{i}(h, t) \pi R_{i n}^{2} N d h-\int_{0}^{H} 2 \pi R_{i n} N n_{i}(h, t) d h=Q_{W 2} c_{W 2, i}(t)
$$

- for the organic phase:

$$
Q_{A 1} c_{A 1, i}\left(t-\tau_{k A}\right)+\int_{0}^{H} 2 \pi R_{i n} N n_{i}(h, t) d h=Q_{A 2} c_{A 2, i}(t)
$$

In general, an intensive flow of phases through the contactor is used consequently in the above equations, the residence time of particular phases in the membrane contactor can be neglected thus corresponding to the lack of mass accumulation in it. For the co-current flow, the density of mass flux of the $i$-th component extracted through membrane pores is described by the relation:

$$
n_{i}(t)=k_{W, i} \frac{\left(c_{W 1, i}-\frac{c_{A 1, i}}{P_{i}}\right)+\left(c_{W 2, i}-\frac{c_{A 2, i}}{P_{i}}\right)}{2}
$$

where:

$$
P_{i}=\frac{c_{A, i}^{*}}{c_{W, i}^{*}}
$$

The mass transfer coefficient related to the water phase and inner membrane surface (for the case when membrane pores are filled with the organic phase that flows on the tube side) is determined by the equation:

$$
k_{W, i}=\frac{1}{\frac{1}{A_{\text {out }} \beta_{\text {out }, i} P_{i}}+\frac{1}{A_{m} \beta_{m, i} P_{i}}+\frac{1}{A_{\text {in }} \beta_{\text {in }, i}}} \cdot \frac{1}{A_{\text {in }}}
$$

where $\beta_{m}$ is the diffusion coefficient of mass transport through membrane pores equal to

$$
\beta_{m, i}=\frac{D_{i}}{\kappa l_{m}}
$$

\section{MATERIALS AND METHODS}

The synthesis of the highly hydrophobic product ZAlaPheOMe was chosen as a model system. This compound is a precursor for AlaPhe peptide. To prevent the formation of peptides with configurations 
different than expected and the production of polypeptides, amino acids blocked at the N' or C' terminus, respectively, were used in the synthesis. The substrates were purchased from Bachem (Switzerland). The synthesis reaction was catalysed by thermolysin [EC 3.4.24.27]: protease $\left(M_{w}=34600 \mathrm{~g} \mathrm{~mol}^{-1}\right)$ from Bacillus thermo-proteolyticus rokko (Sigma, USA) according to:

$$
\mathrm{ZAlaOH}+\mathrm{PheOMe} \stackrel{\text { thermolysin }}{\Longleftrightarrow} \text { ZAlaPheOMe }
$$

Because of the enzyme used, the reaction temperature was $60^{\circ} \mathrm{C}$, and the $\mathrm{pH}$ was 7.0 . Under these conditions, the enzyme exhibits its maximum activity (Trusek-Holownia, 2003). A strongly hydrophobic product was extracted to the organic phase, which was ethyl acetate. This solvent is characterised by high solubility of the product (approximately $70 \mathrm{mM}$ ) and low solubility in water, and it does not significantly affect the inactivation of the enzyme used (Trusek-Holownia, 2003). The organic phase was also used as a reservoir for the hydrophobic substrate (ZAlaOH).

Due to the scale of the proposed experimental setup and because the solvent is aggressive towards plastics (ethyl acetate), the membrane module was custom built. Companies that produce membrane contactors do not offer small modules that are resistant to ethyl acetate. In the production of these devices, various membranes and resins used to make the tube sheets were tested. The most suitable materials, mainly because of the ease of maintaining the interface, were capillary polypropylene membranes produced by PolyMem (Warsaw, Poland) and IBIB-PAN (Warsaw, Poland). Their average pore size was $0.20-0.25 \mu \mathrm{m}$. The membranes were attached to the module using an epoxy resin adhesive. Two types of contactors, tentatively called contactor A and contactor B, were produced. The basic parameters of these modules are given in Table 1.

Table 1. Parameters of the membrane contactors

\begin{tabular}{|l|c|c|c|}
\hline \multicolumn{1}{|c|}{ Parameter } & Unit & Module A & Module B \\
\hline Outer module diameter & $\mathrm{Mm}$ & 45 & 22 \\
\hline Inner module diameter & $\mathrm{Mm}$ & 43 & 20 \\
\hline Module (capillary) length & $\mathrm{Mm}$ & 140 & 130 \\
\hline Number of capillaries & - & 10 & 14 \\
\hline Membrane producer & - & IBIB-PAN & PolyMem \\
\hline Outer capillary diameter & $\mathrm{Mm}$ & 2.5 & 2.2 \\
\hline Inner capillary diameter & $\mathrm{Mm}$ & 1.5 & 1.8 \\
\hline Membrane porosity & - & 0.5 & 0.73 \\
\hline Inner surface area of the membranes & $\mathrm{m}^{2}$ & $6.65 \cdot 10^{-3}$ & $1.02 \cdot 10^{-2}$ \\
\hline
\end{tabular}

Calculations were performed to show that the dispersion of values obtained from individual correlations was relatively large; hence, the choice of the appropriate correlation for a given contactor had to be based on preliminary experiments. Correlations (1)-(8) were verified in two series. In the first series, experiments were conducted in a system of water (saturated with ethyl acetate) - ZAlaOH ethyl acetate (saturated with water) at $60^{\circ} \mathrm{C}$. The initial concentration of $\mathrm{ZAlaOH}$ in the water phase was $20 \mathrm{mM}$, and its volume was $3 \cdot 10^{-5} \mathrm{~m}^{3}$. The organic phase volume was $1 \cdot 10^{-5} \mathrm{~m}^{3}$. Measurements were performed for $1.5 \mathrm{~h}$ in a batch mode, with both phases circulating through the membrane contactor in a closed system. The water phase flowed on the tube side, and the organic phase flowed on the shell side. The phase flow corresponded to $\operatorname{Re}_{W} \in(15.8,150.2)$ and $\operatorname{Re}_{A} \in(6.1,25.4)$ for contactor A and $R e_{W} \in(401.2,1906.7)$ and $R e_{A} \in(19.8,60.1)$ for contactor B. The concentration of ZAlaOH was monitored in both phases using an HPLC (Waters) equipped with a C18 column (Waters) and a mobile 
phase of methanol: $\mathrm{H}_{2} \mathrm{O}$ :perchloric acid 65:35:0.05 v/v with a flow rate of $1 \mathrm{~cm}^{3} \mathrm{~min}^{-1}$. Detection was performed at $254 \mathrm{~nm}$.

In the second series of tests, PheOMe was initially added to the water phase to a concentration of $200 \mathrm{mM}$, while the organic phase contained ZAlaOH and ZAlaPheOMe at $40 \mathrm{mM}$ each. The volume of the water phase volume was $3 \cdot 10^{-5} \mathrm{~m}^{3}$ and the organic phase $1 \cdot 10^{-5} \mathrm{~m}^{3}$. The tests were carried out in contactor $\mathrm{A}$ at $R e_{W} \in(15.8,53.2)$ and $R e_{A}=11.1$.

Integration of the enzymatic reaction with extraction in the membrane contactor was performed using a mixed mode. The water phase containing the enzyme at a concentration of $0.005 \mathrm{mM}$ circulated in a closed system. Several reservoirs $\left(V_{A}\right)$ of the organic phase containing the same concentration of substrates were prepared. As the substrates were depleted, subsequent reservoirs were connected to the system. This corresponded to a step change of concentration in the organic phase contacting the water phase. This method allowed us to use the enzyme throughout its period of relatively high activity, i.e., up to $50 \%$ activity.

In this work, verification was carried out using the following parameters:

- Water phase volume $-1.7 \mathrm{dm}^{3}$

- Organic phase volume $-2.0 \mathrm{dm}^{3}$

- Temperature of the water and organic phases $-60^{\circ} \mathrm{C}$

- Enzyme concentration in the water phase $-0.005 \mathrm{mM}$

- Initial concentrations of reagents:

$\begin{array}{lll} & \text { Water phase } & \text { Organic phase (each charge) } \\ \text { PheOMe } & 250 \mathrm{mM} & 75 \mathrm{mM} \\ \text { ZAlaOH } & 30 \mathrm{mM} & 200 \mathrm{mM} \\ \text { ZAlaPheOMe } & <0.6 \mathrm{mM} & 35 \mathrm{mM} \\ \text { Number of charges }-3 & \end{array}$

\section{RESULTS AND DISCUSSION}

\subsection{Determination of model parameters}

\subsubsection{Reaction kinetics}

In the description of the enzymatic synthesis of ZAlaPheOMe, the mechanism of tetrahedral complex formation with a random sequence of substrates was assumed. A previously (Trusek-Holownia, 2003) developed rate equation was used. At $60^{\circ} \mathrm{C}, \mathrm{pH} 7.0$ and the enzyme used (thermolysin), taking into account its inactivation, the equation is as follows:

$$
r\left[\frac{\mathrm{mM}}{\mathrm{s}}\right]=\frac{0.222\left[\frac{1}{\mathrm{~s}}\right] \cdot c_{W, \text { PheOMe }} \cdot c_{W, \text { ZAlaOH }} \cdot c_{E}(0) \cdot e^{-2.0 \cdot 10^{-6}\left[\frac{1}{\mathrm{~s}}\right] \cdot t[\mathrm{~s}]}}{c_{W, \text { ZAlaOH }} \cdot c_{W, \text { PheOMe }}+149.3 \cdot c_{W, \text { ZAlaOH }}+11.5 \cdot c_{W, \text { PheOMe }}+1717\left[\mathrm{mM}^{2}\right]}
$$

\subsubsection{Partition coefficient of reactants}

The studied system was characterised by the limited solubility of the components in both phases (Table 2), which reduces the applicability of the reactants and affects the technique used for their replenishment. 
Table 2. Solubility of reactants $[\mathrm{mM}]$ at $60^{\circ} \mathrm{C}$

\begin{tabular}{|l|c|c|c|}
\hline & PheOMe & ZAlaOH & ZAlaPheOMe \\
\hline Water phase (buffer, $\mathrm{pH}=7.0$, saturated with ethyl acetate) & 1406 & 30 & 0.76 \\
\hline Organic phase (ethyl acetate saturated with buffer) & 810 & 421 & 71 \\
\hline
\end{tabular}

The partition coefficient defined by Eq. (14) assumed a constant value of 278.0 for the product at $60^{\circ} \mathrm{C}$. For PheOMe, the partition coefficient was dependent on its concentration in the water phase and was described by the equation:

$$
\begin{aligned}
& P_{\text {ZAlaOH }}=\alpha c_{W, \text { ZAlaOH }}^{*}+b+\frac{c}{c_{W, \text { ZAlaOH }}^{*}} \\
& P_{\text {PheOMe }}=0.625-1.4 \cdot 10^{-3} c_{W, \text { PheOMe }}^{*}
\end{aligned}
$$

For $\mathrm{ZAlaOH}$, the partition coefficient depended on both its concentration in the system and the PheOMe concentration and was described by the equation:

$$
P_{\text {ZAlaOH }}=a c_{W, Z A l a O H}^{*}+b+\frac{c}{c_{W, \text { ZAlaOH }}^{*}}
$$

where:

$$
\begin{aligned}
& a=0.0663+5.0 \cdot 10^{-4} c_{A, \text { PheOMe }}^{*}-9.1 \cdot 10^{-7} c_{A, \text { PheOMe }}^{*_{2}} \\
& b=6.1 \cdot 10^{-5} c_{A, \text { PheOMe }}^{*_{2}}+0.0312 c_{A, \text { PheOMe }}^{*}-0.5398 \\
& c=0.32 e^{-0.0124 c_{A, \text { PheOMe }}^{*}}
\end{aligned}
$$

A nonlinear change in the partition coefficient combined with the non-linearity of the rate equation required the use of numerical methods to solve the presented system of model equations.

\subsubsection{Mass transport in the membrane contactor}

To determine the mass transfer coefficient using Eqs. (1)-(8), physical properties, including the kinematic diffusion coefficient of the compound in both phases, should be know. These values were calculated from the Othmer-Thakar equation (Bretsznajder, 1962) using the molar volumes calculated using the Le Bas method (Bretsznajder, 1962). Results are presented in Table 3.

Table 3. Values of the kinematic diffusion coefficient $\left[\mathrm{m}^{2} \mathrm{~s}^{-1}\right]$ at $60^{\circ} \mathrm{C}$

\begin{tabular}{|l|c|c|}
\hline \multicolumn{1}{|c|}{ Reactant } & Water phase & Organic phase \\
\hline ZAlaOH; $M_{w}=223.23\left[\mathrm{~g} \mathrm{~mol}^{-1}\right]$ & $1.28 \cdot 10^{-9}$ & $3.37 \cdot 10^{-9}$ \\
\hline PheOMe; $M_{w}=215.68\left[\mathrm{~g} \mathrm{~mol}^{-1}\right]$ & $1.37 \cdot 10^{-9}$ & $3.60 \cdot 10^{-9}$ \\
\hline ZAlaPheOMe $; M_{w}=402.45\left[\mathrm{~g} \mathrm{~mol}^{-1}\right]$ & $0.89 \cdot 10^{-9}$ & $2.32 \cdot 10^{-9}$ \\
\hline
\end{tabular}

Experimental determination of mass transfer coefficients was carried out in the batch process, with the two phases circulating through the membrane contactor in a closed system. Under such conditions, for the case of mass transfer from the aqueous to organic phase, the mass flux is described by the equation:

$$
V_{A} \frac{d c_{A, i}(t)}{d t}=k_{W, i} A\left(c_{W, i}(t)-\frac{c_{A, i}(t)}{P_{i}}\right)
$$


The mass transfer coefficient can be calculated from Equation (20) provided the concentrations in both phases are known. In the case of the partition coefficient, which is dependent on concentration, Eq. (20) cannot be integrated, and its differential form was used to determine $\mathrm{d} c / \mathrm{d} t$ from the curve $c=f(t)$ during data processing.

The first series of verification tests was performed using the water phase-ZAlaOH-organic phase system, applying contactors A and $\mathrm{B}: \operatorname{Re}_{W} \epsilon(15.8,150.2)$ and $\operatorname{Re}_{A} \epsilon(6.1,25.4)$ for contactor $\mathrm{A}$ and $R e_{W}$ $\epsilon(401.2,1906.7)$ and $\operatorname{Re}_{A} \epsilon(19.8,60.1)$ for contactor B. The experimental values of the mass transfer coefficient calculated from Eq. (20) were compared with those calculated from Eq. (15) using the combination of all presented correlations (Eq. (1)-(8)). A change in the mass transfer coefficient as Re was increased in both phases was found to be small. For the organic phase, the mass transfer coefficient was proportional to $R e^{0.6}$, and for the water phase, it was proportional to $R e^{0.33}$. An increase in the flow rate was accompanied by problems associated with maintaining the interface.

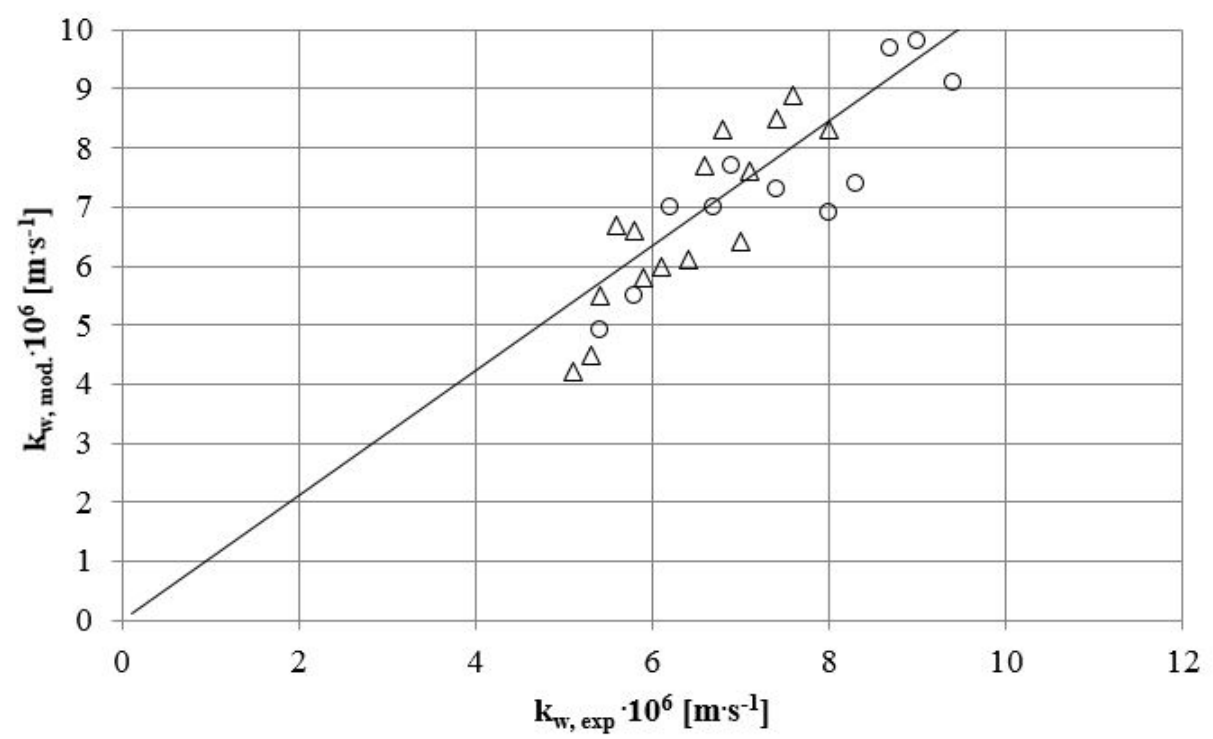

Fig. 2. Comparison of experimental values and those obtained using Equation (3) - tube side $+(5)-$ shell side, for contactor $\mathrm{A}(\Delta)$ and contactor $\mathrm{B}(\mathrm{o})$.

The best conformity (Fig. 2) was obtained by calculating the transfer coefficient on the tube side using Equation (3) and on the shell side using Equation (5). The average relative error was $8.8 \%$ for module A and $10.2 \%$ for module B. Therefore, in further tests, module A was used. Deviations between the calculated and experimental values of mass transfer coefficient allow us to conclude that when designing a contactor, a $20 \%$ excess of mass transfer area is recommended. This excess is similar to the standard procedure assumed in the design of this type of apparatus, and it does not significantly affect the cost of the module.

The final verification of the mass transport kinetics was performed for the system containing all of the reactants. In addition to the selected correlations, the previously determined partition coefficients were also verified. Due to analytical problems complicating the determination of very small concentration changes in the water phase, the transfer coefficients for ZAlaPheOMe were determined using only the correlations.

Table 4 presents a comparison of the experimentally obtained values of the mass transfer coefficient with those calculated using the correlations (Eqs. (3) and (5)) and a determination of the percentages of the individual components of mass transfer resistance. The average relative errors for ZAlaOH and PheOMe were 3.8 and $10.2 \%$, respectively. 
Table 4. Characteristics of mass transfer in membrane contactor $\mathrm{A}\left(\operatorname{Re}_{A}=11.1\right)$

\begin{tabular}{|c|c|c|c|c|c|}
\hline \multirow{2}{*}{$\operatorname{Re}_{W}$} & \multicolumn{2}{|c|}{$k_{W, i} \cdot 10^{-6}\left[\mathrm{~m} \mathrm{~s}^{-1}\right]$} & \multicolumn{3}{|c|}{ mass transfer resistance $[\%]$} \\
\hline & Calculated & Experimental & Water phase & Membrane & Organic phase \\
\hline & \multicolumn{5}{|c|}{ ZAlaOH } \\
\hline 15.8 & 3.8 & 3.6 & 82.7 & 5.3 & 12.0 \\
\hline 21.7 & 4.2 & 4.2 & 81.2 & 5.9 & 12.9 \\
\hline 39.3 & 4.9 & 4.6 & 78.0 & 6.8 & 15.1 \\
\hline \multirow[t]{2}{*}{53.2} & 5.3 & 5.1 & 76.2 & 7.4 & 16.4 \\
\hline & \multicolumn{5}{|c|}{ PheOMe } \\
\hline 15.8 & 2.0 & 2.1 & 33.8 & 20.7 & 45.5 \\
\hline 21.7 & 2.1 & 2.3 & 31.2 & 21.5 & 47.3 \\
\hline 39.3 & 2.2 & 2.4 & 27.5 & 22.6 & 49.9 \\
\hline \multirow[t]{2}{*}{53.2} & 2.3 & 2.7 & 24.7 & 23.5 & 51.8 \\
\hline & \multicolumn{5}{|c|}{ ZAlaPheOMe } \\
\hline 15.8 & 3.7 & - & $\approx 100$ & $\approx 0$ & $\approx 0$ \\
\hline 21.7 & 4.3 & - & $\approx 100$ & $\approx 0$ & $\approx 0$ \\
\hline 39.3 & 4.8 & - & $\approx 100$ & $\approx 0$ & $\approx 0$ \\
\hline 53.2 & 5.1 & - & $\approx 100$ & $\approx 0$ & $\approx 0$ \\
\hline
\end{tabular}

Due to a very high partition coefficient, the mass transfer resistances for ZAlaPheOMe were the highest. Practically, the entire mass transfer resistance was concentrated in the water phase. Similarly, in the case of mass transfer for $\mathrm{ZAlaOH}$ (which is also a hydrophobic component), the largest effect on the transport rate was the transfer in the water phase. The mass transfer resistances for the hydrophilic components of the system, i.e., PheOMe, were relatively balanced.

\subsection{An integrated process - reaction with extraction}

A model of the system was analysed to determine the optimal ranges of variability for its parameters:

- the concentration of reactants, including the enzyme,

- the volumes of both circulating phases,

- a membrane surface ensuring the required mass transfer,

- enzyme activity $>50 \%$ of the initial activity,

- number of charges in the process.

Analysing the solubility of the individual reactants in both phases, changes in their concentrations during the reaction, and the reaction rates as well as partition coefficients that depend on the concentration, the initial composition of substrates in both phases was determined. For a phase ratio of approximately $1: 1 \mathrm{v} / \mathrm{v}$, the concentration of $\mathrm{ZAlaOH}$ in the water phase should be within the range of $22-30 \mathrm{mM}$ and that in the organic phase should be $175-220 \mathrm{mM}$. For PheOMe, this range is 220-270 $\mathrm{mM}$ for the water phase and 60-70 $\mathrm{mM}$ for the organic phase. Comparing the dynamics of the production decrease caused by enzyme inactivation with the cost of the downtime necessary for its replacement, it was assumed that the effective duration of enzyme use was 300 hours. During this period, using the batch process, several batches could be completed (only the exchange of the organic phase was assumed). Due to enzyme inactivation, the reaction rate decreased, and the duration of the subsequent batch was thus increased. Because of its cost, the enzyme should be added at a concentration that would allow for its maximum utilisation (optimally, in the range of the $1^{\text {st }}$-order kinetics for the enzyme), which corresponded to an enzyme concentration of 0.003-0.006 $\mathrm{mM}$ in this work. To ensure the required mass flux between the two phases, an appropriate relationship between 
the mass transfer area and the volume of the reaction system was required so that at a specified substrate concentration, a determined amount of the product is yielded.

For the above-mentioned range of concentrations and for contactor A, the volumes of both phases were selected on the basis of model calculations. The water phase should not exceed 2.5 litres. Additionally, the organic phase volume could be $15-25 \%$ larger.

For values that satisfied the above assumptions, tests were performed to verify the proposed model of the bioreactor with the phase contactor. Results are shown in Figs. 3a-e. The line indicates the expected concentrations based on model calculations, and the points correspond to the experimental values.

a)

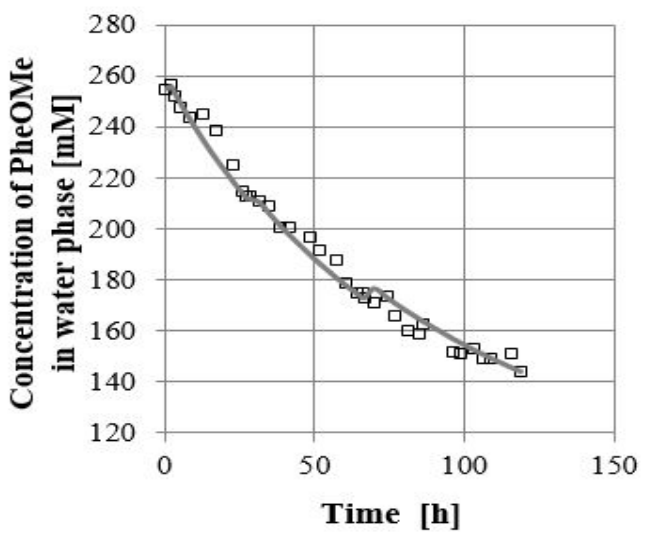

c)

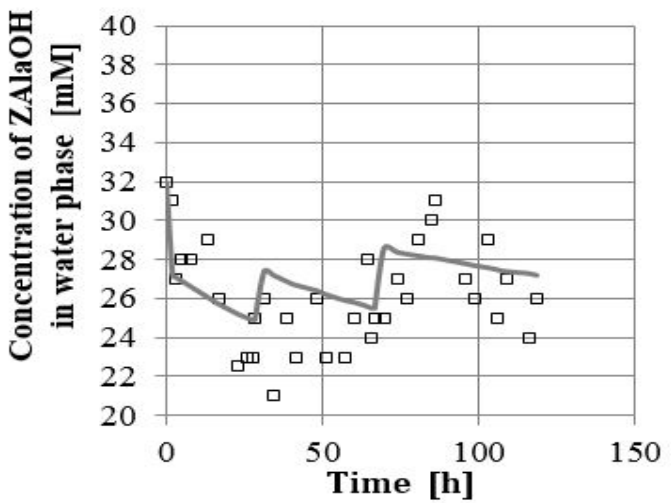

b)

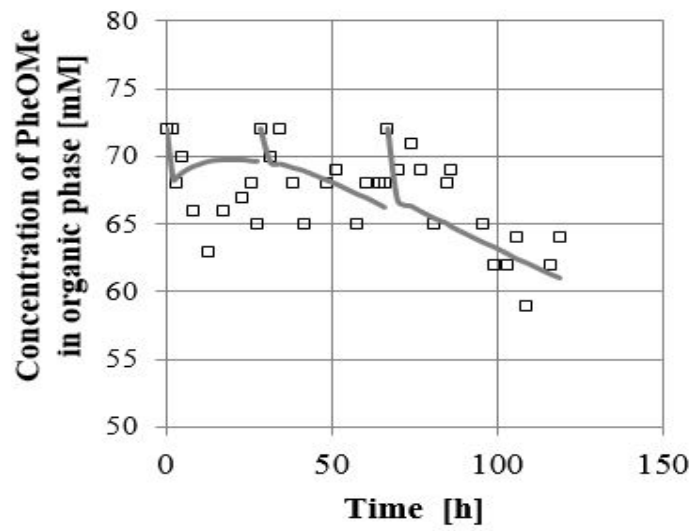

d)

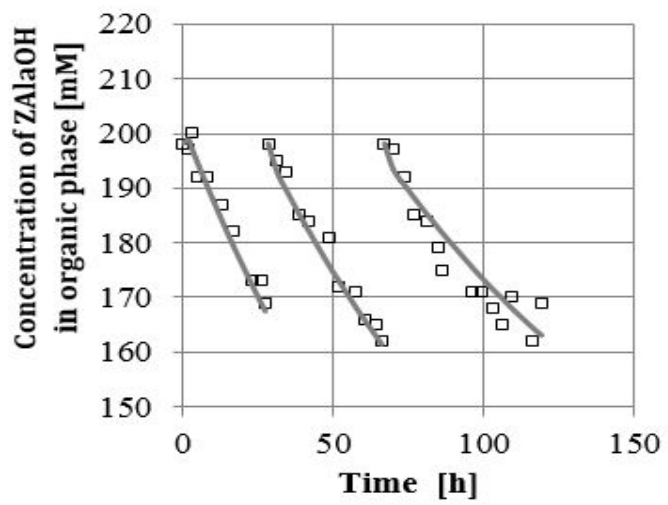

e)

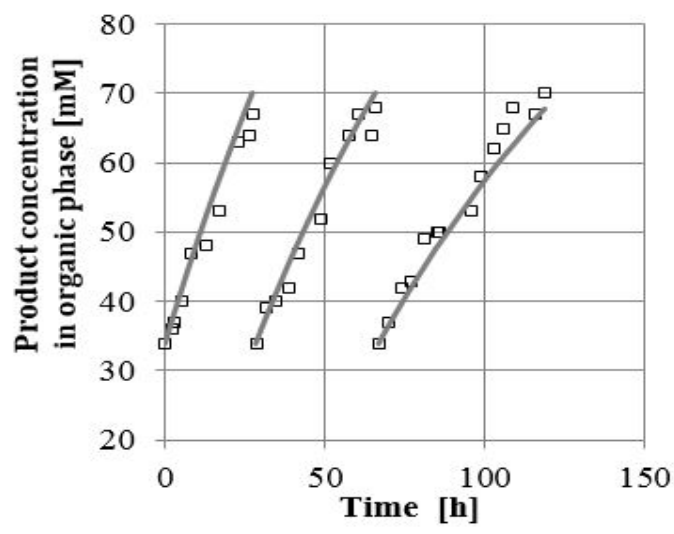

Fig. 3. Experimental (points) and model (line) concentration changes during the process 


\section{CONCLUSIONS}

The system of an enzyme reactor integrated with a membrane contactor used in these experiments is an interesting design of an apparatus enabling to collect hydrophobic reaction products and supply hydrophobic substrates to the reaction phase. Experiments showed a high effectiveness of this multifunctional reactor. The high rate of the mass transfer made it possible to maintain an advantageous range of substrate concentrations in the reaction phase and almost immediate collection of the product. Despite the use of an aggressive organic solvent, the applied membrane phase contactor worked flawlessly. The contactor was cheaper and easier to use than stirred-tank or column extractors.

The organic phase received in batches contained the product at a concentration close to its solubility in the organic solvent and impurities in the form of a hydrophobic substrate. Because the substrate had an about hundred times lower value of the partition coefficient than that for the product $(P=278)$, the phase containing the product could be purified by stirred extraction of the substrate to water.

Due to the relatively large dispersion between the values of the mass transfer coefficients in the membrane modules obtained using the correlations reported in the literature verification tests are recommended before membrane selecting.

This work was financed by a statutory activity subsidy from the Polish Ministry of Science and Higher Education from the Faculty Chemistry of Wroclaw University of Technology No. S40616/Z0311.

\section{SYMBOLS}

$\begin{array}{ll}A & \text { mass transfer surface, } \mathrm{m}^{2} \\ c & \text { concentration, } \mathrm{mM} \\ c^{*} & \text { equilibrium concentration, } \mathrm{mM} \\ D & \text { diffusion coefficient, } \mathrm{m} \mathrm{s}^{-2} \\ d & \text { diameter, } \mathrm{m} \\ G r & \text { Graetz number } \\ H & \text { module length, } \mathrm{m} \\ h & \text { length, } \mathrm{m} \\ k & \text { mass transfer coefficient, } \mathrm{m} \mathrm{s}^{-1} \\ l_{m} & \text { membrane thickness, } \mathrm{m} \\ M_{w} & \text { molecular weight, } \mathrm{g} \text { mol }{ }^{-1} \\ N & \text { number of capillaries in module } \\ n & \text { mass transfer density, mol s } \mathrm{m}^{-2} \\ P & \text { partition coefficient } \\ Q & \text { volume stream, } \mathrm{m}^{3} \mathrm{~h}^{-1} \\ R e & \text { Reynolds number } \\ R_{i n} & \text { internal membrane radius, } \mathrm{m}^{-1} \\ r & \text { reaction rate, } \mathrm{mM} \mathrm{s}^{-1} \\ S c & \text { Schmidt' number } \\ S h & \text { Sherwood number } \\ t & \text { time, } \mathrm{s} \\ V_{A} & \text { organic phase volume, } \mathrm{m}^{3} \\ V_{R} & \text { reactor volume, } \mathrm{m}^{3}\end{array}$

Greek symbols

$\beta \quad$ individual mass transfer coefficient, $\mathrm{m} \mathrm{s}^{-1}$ 
$\varphi \quad$ ratio of capillaries volume to whole module volume

$\kappa \quad$ membrane tortuosity

$\tau_{k} \quad$ residence time in membrane module, $\mathrm{s}$

$\begin{array}{ll}\text { Subscripts } & \\ A & \text { organic phase } \\ E & \text { enzyme } \\ h y d r & \text { hydraulic } \\ i & \text { reagent } \\ \text { in } & \text { internal side (surface) } \\ m & \text { membrane } \\ W & \text { water phase } \\ \text { out } & \text { outer side (surface) } \\ 0 & \text { initial conditions } \\ 1,2,3 & \text { stream number }\end{array}$

\section{REFERENCES}

Agrahari G.K., Verma N., Bhattacharya P.K., 2011. Application of hollow fiber membrane contactor for the removal of carbon dioxide from water under liquid-liquid extraction mode. J. Membrane Sci., 375, 323-333. DOI: 10.1016/j.memsci.2011.03.060.

Anzai J., Lee S., Osa T., 1989. Enzyme sensors based on an ion-sensitive field effect transistor coated with Langmuir-Blodgett membranes. Chem. Pharm. Bull., 37, 3320-3322.

Bretsznajder S., 1962. Własciwości cieczy i gazow. WNT, Warszawa, Poland (in Polish).

Cerovsky V., Jakubke H.-D., 1994. Acyl transfer reaction catalyzed by native and modified $\alpha$-chymotrypsin in acetonitrile with low water content. Enzyme Microb. Tech., 16, 596-601. DOI: 10.1016/0141-0229(94)90125-2.

Cerovsky V., Martinek K., 1989. Free chymotrypsin-catalysed synthesis of peptide bond in aliphatic alcohols with low water content. Collect. Czech. Chem. C, 54, 266-276.

Chang H., Furusaki S., 1991. Membrane bioreactors: Present and prospects. Adv. Biochem. Eng. Biotech., 44, 2764.

Cunha T., Aires-Barros R., 2002. Large-scale extraction of proteins. Mol. Biotechnol., 20, 1, 29-40. DOI: 10.1385/MB:20:1:029.

Ceynowa J., 1974. Kataliza w rektorach z membranami enzymatycznymi. Biotechnologia, 1(24) 64-80 (in Polish).

Dabkowska K., Pilarek M., Szewczyk K., 2012. Substrate inhibition in lipase - catalased transestrification of mandelic acid with vinyl acetate. Chem. Process Eng., 33, 539-546. DOI: 10.2478/v10176-012-0044-8.

Hossain M.M., Dean J., 2008. Extraction of penicillin G from aqueous solutions: Analysis of reaction equilibrium and mass transfer. Separ. Purif. Technol., 62, 437-443. DOI: 10.1016/j.seppur.2008.02. 012.

Huang H., Yang S.-T., Ramey D.E., 2004. A hollow-fiber membrane extraction process for recovery and separation of lactic acid from aqueous solution. Appl. Biochem. Biotechnol., 114, 671-688. DOI: 10.1385/ABAB:114:1-3:671.

Jakubke H.-D., Kuhl P., Konnecke A., 1985. Basic principles of protease - catalyzed peptide bond formation. Angew. Chem. Int. Edit., 24, 2, 85-93.

Jin J.N., Lee S.H., Lee S.B., 2003. Enzymatic production of enantiopure ketoprofen in a solvent-free two-phase system. J. Mol. Catal. B: Enz., 26, 209-216. DOI: 10.1016/j.molcatb.2003.06.004.

Koltuniewicz A., Modelski S., Witek A., 2012. Designing of membrane contactors with cross-counter current flow. Chem. Process Eng., 33, 573-583. DOI: 10.2478/v10176-012-0047-5.

Ma C.Q., Li J.C., Qiu J.H., Wang M., Xu P., 2006. Recovery of pyruvic acid from biotransformation solutions. Appl. Microbiol. Biotechnol., 70, 308-314. DOI: 10.1007/s00253-005-0072-0.

Matsumae H., Furui M., Shibatani T., Tosa T., 1994. Production of optically active 3-phenylglycidic acid ester by the lipase from Serratia marcescent on a hollow-fiber membrane reactor. J. Ferment. Bioeng., 78, 1, 59-63. DOI: 10.1016/0922-338X(94)90179-1. 
Mizushige T., Kanegawa N., Yamada A., Ota A., 2013. Aromatic amino acid-leucine dipeptides exhibit anxiolytic-like activity in young mice. Neurosci. Lett., 543, 126-129. DOI: 10.1016/j.neulet.2013.03.043.

Nomoto F., Hirayama Y., Ikunaka M., Inoue T., Otsuka K., 2003. A practical chemoenzymatic process to access (R)-quinuclidin-3-ol on scale. Tetrahedron: Asymmetry, 14, 1871-1877. DOI: 10.1016/S0957-4166(03)00363$\mathrm{X}$.

Penci M.C., Constenla D.T., Carelli A.A., 2010, Free-fatty acid profile obtained by enzymatic solvent-free hydrolysis of sunflower and soybean lecithins. Food Chem., 120, 332-338. DOI: 10.1016/j.foodchem.2009.10.025.

Payne J.W., Payne G.M., Gupta S., Marshall N.J., Grail B.M., 2001, Conformational limitations of glycylsarcosine as a prototypic substrate for peptide transporters. Biochim. Biophys. Acta, 1514, 65-75.

Pohorecki R., Moniuk W. Bielski P., Zdrojkowski A., 2001. Modelling of the coalescence/redispersion processes in bubble columns. Chem. Eng. Sci., 56, 6157-6164. DOI: 10.1016/S0009-2509(01)00214-7.

Sentandreu M.A., Toldra F., 2007. Evaluation of ACE inhibitory activity of dipeptides generated by the action of porcine muscle dipeptidyl peptidases. Food Chem., 102, 511-515. DOI: 10.1016/j.foodchem.2006.04.018.

Sisak C., Nagy E., Burfeind J., Schugerl K., 2000. Technical aspects of separation and simultaneous enzymatic reaction in multiphase enzyme reactors. Bioprocess Engineering, 23, 503-512. DOI: 10.1007/s004499900187.

Trusek-Holownia A., 2003. Synthesis of ZAlaPheOMe, the precursor of bitter dipeptide in the two-phase ethyl acetate-water system catalyzed by thermolysin. J. Biotechnol., 102, 153-163. DOI: 10.1016/S01681656(03)00024-5.

Trusek-Holownia A., 2005. Improvement of process productivity and product purity by the application of a membrane phase contactor in enzymatic conversion. Separ. Purif. Technol., 41, 267-274. DOI: 10.1016/j.seppur.2004.03.018.

Trusek-Holownia A., Noworyta A., 2007. An integrated process: Ester synthesis in an enzymatic membrane reactor and water sorption. J. Biotechnol., 130, 47-56. DOI: 10.1016/j.jbiotec.2007. 03.006.

Vercruysse L., Morel N., Camp J.V., Szust J., Smagghe G., 2008. Antihypertensive mechanism of the dipeptide Val-Tyr in rat aorta. Peptides, 29, 261-267. DOI: 10.1016/j.peptides.2007.09.023.

Villa E.M.A., Wichmann R., 2005. Membranes in the enzymatic synthesis of biotensides from renewable sources. Catal. Today, 104, 318-322. DOI: 10.1016/j.cattod.2005.03.080.

Vu T.H.T., Au H.T., Nguyen T.H.T., Nguyen T.T.T., Do M.H., Bui N.I., Essayem N., 2013. Esterification of lactic acid by catalytic extractive reaction: an efficient way to produce a biosolvent composition. Catal. Lett., 143, 950-956. DOI: 10.1007/s10562-013-1077-4.

Wasewar K.L., Heesinkb A.B.M., Versteegb G.F., Pangarkara V.G., 2004. Intensification of conversion of glucose to lactic acid: equilibria and kinetics for back extraction of lactic acid using trimethylamine. Chem. Eng. Sci., 59, 2315-2320. DOI: 10.1016/j.ces.2003.11.023.

Yankov D., Molinier J., Albet J., Malmary G., Kyuchoukov G., 2004. Lactic acid extraction from aqueous solutions with tri-n-octylamine dissolved in decanol and dodecane. Biochem. Eng. J., 21, 63-71. DOI:10.1016/j.bej.2004.03.006.

Received 30 June 2015

Received in revised form 30 November 2015 Accepted 01 December 2015 